\title{
Genetics of life history in Daphnia magna. I. Heritabilities at two food levels
}

\author{
DIETER EBERT*, LEV YAMPOLSKY† \& STEPHEN C. STEARNS \\ Institut für Zoologie, Universität Basel, Rheinsprung 9, CH-4051, Basel, Germany
}

\begin{abstract}
Broad- and narrow-sense heritabilities for several life-history traits were estimated from 23 mother-daughter pairs of Daphnia magna at two food levels. Sexually produced daughter clones were obtained from a field collection of ephippial females (mothers) and the subsequent hatching of their ephippial eggs (daughters). Mother and daughter clones were maintained by parthenogenetic reproduction. Heritabilities of adult body-length of eight successive instars were the highest estimates of all in good food, but the lowest of all in poor food. For clutch size and body-length of offspring from the first six clutches, narrow- and broad-sense heritabilities were about equal and lower in poor food than in good food. The amount of genetic variation present would allow a response to selection on clutch size and offspring length in both environments but adult length only in good food. For age at maturity we found no additive genetic variance. We found no difference in broad-sense heritabilities between mother clones, representing the last generation after a period of asexual reproduction, and their sexually produced offspring. This suggests that genetic variance does not increase after one sexual generation or that it was not reduced before. Differences in heritabilities between environments are discussed with reference to the enlarged phenotypic variances that result from variation in juvenile instar number. Targeted growth could explain the pronounced differences in the heritabilities of adult length between environments.
\end{abstract}

Keywords: Cladocera, Daphnia, environment, heritability, life history, quantitative genetics.

\section{Introduction}

Parent-offspring regression is a tool commonly used to estimate the genetic similarity between parents and their sexually produced offspring (Falconer, 1981; Bulmer, 1985), although it suffers from some problems that are often ignored in population studies (Henrich, 1989). Measurements of the traits in parents and daughters may be taken at the same age, but with a time lag of one generation. When measurements are made at the same time, parents are much older than offspring and might have been subject to selection (van Noordwijk, 1984; Henrich, 1989) or to age effects. Maternal effects pose additional problems. Even when eggs or newborn are separated from their mothers as early as possible, maternal effects may still occur. Some solutions exist to circumvent these problems, but they require large experimental designs (Falconer, 1981) unless organisms which reproduce both sexually and asexually are used.

*Correspondence \& present address: University of Oxford, Department of Zoology, South Parks Road, Oxford OX1 3PS, UK.

†Present address: N. I. Vavilov Institute of General Genetics, Academy of Science, Gubkin str., 3 GSP-1, V-333, Moscow, Russia.
In a cyclic, parthenogenic species like aphids or most cladocerans, all these problems can be circumvented because mothers as well as their sexually produced offspring can be cloned for many generations before variance components are estimated. Further, total genetic variance can easily be estimated, for each clone can be tested in several replicates within and among environments.

The data gathered here address a point commonly made about populations with clonal structure: genetic variance should decline during the asexual phase as clones are eliminated by selection (Maynard Smith, 1978; Lynch, 1984; Vrijenhoeck, 1984). Lynch \& Gabriel (1983) and Lynch (1985) argued that in cyclic parthenogens this decline is compensated by mutations and periodic sex which releases 'hidden genetic variance' (Lynch \& Gabriel, 1983), allowing cyclic parthenogens to have much higher rates of phenotypic evolution than bisexual organisms. Up to now, no data have been available from a cyclic parthenogen to compare the genetic variance of asexual lines and of their sexual derivatives.

For cyclic, parthenogenetic Daphnia, problems with crossing laboratory strains makes it difficult to estimate 
additive genetic variance casily (but sec De Meester, 1991). By using ephippia-carrying females taken from the field, we overcame this problem and were able to estimate genetic variance by use of single parentoffspring regression. We were interested in the following questions: (i) is there additive genetic variation present in Daphnia? (ii) Is there evidence that genetic variation declines during the asexual phase and is reestablished after a sexual generation? (iii) What causes differences in heritability estimates between environments?

\section{Material and methods}

\section{Origin of clones}

Clones of Daphnia magna originated from a permanent. shallow pond near Forchheim in south-west Germany ( $\mathrm{sec}$ Ebert, 1991 for more details). Samples were taken at regular intervals and checked for ephippial females. On 21 May, 1990, 10 per cent $(n=350)$ of all adult females bore ephippia. Earlier and later in this year ephippia production was never as high (Ebert, in preparation). We collected 120 females with ephippia from the pond population and kept them singly in the laboratory at lake temperature and under the natural light/dark cycle. After these 'mother' females moulted. the ephippia were collected, dried and stored at $5^{\circ} \mathrm{C}$ in the dark for 2 months. The parthenogenetical offspring subsequently produced by these mothers were used to establish "mother laboratory clones".

Eggs from the ephippia were hatched at $18^{\circ} \mathrm{C}$ and continuous light. Ninety-two per cent of the ephippia contained eggs. but in only 35 per cent of them did at least one egg complete development. These ex-ephippial offspring were used to found clones of the 'daughter' generation. We obtained 2.3 pairs (families) of mother and daughter clones.

\section{Electrophoresis}

Clones were characterized electrophoretically by means of cellulose-acetate electrophoresis (Trisglycine buffer, $\mathrm{pH} 8.5$ ) for their genotypes at three loci: phospho-gluco-isomerase (Pgi), esterase (Est) and amylase (Amy). Staining procedures followed Wolf (1982). Beside our laboratory clones, we typed samples of non-ephippial females, ephippial females and males which were taken from the field together with the 'mother' clones. Since ephippial females and males were relatively rare compared with non-ephippial females, a larger sample of plankton was searched through to collect enough males and ephippial females. Therefore the samples of the three groups cannot be pooled. Likelihood ratio tests (Sokal \& Rohlf, 1981) were used to compare genotype frequencies.

\section{Experiments}

Single females were kept at $20 \pm 1{ }^{\circ} \mathrm{C}$ and $16: 8$ light/ dark with Ankistrodesmus gracilis as the only food. In high food conditions we added $10^{5}$ cells $\mathrm{ml}^{-1}$, in low food $10^{4}$ cells $\mathrm{ml}^{-1}$ cvery day. Standard experimental conditions were the same as Ebert (1991).

For each food level one reproductive female from each of the 46 clones was isolated from the stem cultures. From each of these mothers, we isolated three neonates in separate glasses, representing clonal replicates (46 clones $\times 3$ replicates $\times 2$ food levels $=276$ lines). These 276 females represent the first generation of three generations that were kept under standard conditions. Measurements were not taken before the third generation to avoid maternal effects due to common environment (Lynch, 1984). The second generation started with a newborn from the second clutch of gencration one, the third and final generation started with a newborn from the second, third or fourth clutch of generation two. By avoiding first clutch offspring we reduced the variance for body-length at birth, which has a strong impact on Daphnia lifehistory (Green, 1954, 1956; Ebert, 1991). Lines were randomized and their locations within the climate chamber were changed daily after feeding. We lost four lines in the third gencration before maturity through death for reasons unknown. All other females reproduced, but some died before they reached the seventh adult instar.

In the third generation single females of all lines were checked once a day for exuvia. Number and time of moultings were recorded and total body-length (excluding the spina but including the base of the spina) at birth, at the adolescent instar and at each of the first seven adult instars was measured. Sizes of clutches 1-6 and the body-length of four randomly chosen neonates from each of these clutches were recorded. Mean length of neonates per clutch was used in the analysis.

\section{Data analysis}

Phenotypic variance, $V_{\mathrm{P}}$, may be partitioned into environmental $V_{\mathrm{F}}$ and genetic components $V_{\mathrm{G}}$, $V_{\mathrm{P}}=V_{\mathrm{E}}+V_{\mathrm{i}}+\operatorname{Cov}_{\mathrm{GF}}$. $\operatorname{Cov}_{\mathrm{GE}}$. the genotypeenvironment covariance is zero in a randomized experiment (Falconer, 1981). In clonal organisms $V_{\mathrm{G}}$ can be estimated from the among clone variance component, $V_{\mathrm{k}}$, from the within clone variance component. We used maximum-likelihood method (PROC VARCOMP; SAS, 1990) for this. Significance 
levels were obtained from one-way ANOvas with clones as the main effect.

The genetic variance can be further partitioned into the additive genetic variance $V_{\mathrm{A}}$ and non-additive genetic variance $V_{\mathrm{NA}} \cdot V_{\mathrm{G}}=V_{\mathrm{A}}+V_{\mathrm{NA}}$ (Falconer, 1981). Maternal cytoplasmic effects will contribute to $V_{\mathrm{G}}$. Our design did not allow to estimate this effect. $V_{\mathrm{A}}$ can be estimated by parent-offspring regression, where in the case of one parent and one offspring the slope equals $\frac{1}{2} V_{\mathrm{A}}+\frac{1}{4} V_{\mathrm{AA}} . V_{\mathrm{AA}}$, the variance due to additiveadditive interaction, can usually be ignored (Falconer, 1981). In our experimental design we had three replicates of each mother clone and three replicates of each daughter clone. We combined each of the three mothers with each of the three daughters, obtaining nine $(3 \times 3)$ pairs for the parent-offspring regression. This method improves the quality of the slope estimate, although the degrees of freedom are too large. Therefore, significant levels of $V_{\mathrm{A}}[2 \times$ slope of parent-offspring regression (Falconer, 1981)] were obtained using a nested ANOVA (PROC GLM; SAS, 1990) with clones nested within families. For negative slopes (two non-significant cases) $V_{\mathrm{A}}$ was set to zero.

Parent-offspring regression gives $V_{\mathrm{A}}$ estimates only for the parents (Falconer, 1981). Therefore, $V_{G}$ was also estimated by including only the mother clones in the analysis. In comparing significance levels of $V_{\mathrm{A}}$ and $V_{\mathrm{G}}$ estimates, one must recall that $V_{\mathrm{A}}$ estimates are based on average on half of the genes shared by mothers and their sexual daughters. Therefore $V_{\mathrm{A}}$ estimates are more influenced by random variation and less likely to be significant than $V_{\mathrm{G}}$ estimates, even when they are of equal magnitude. By measuring offspring length and clutch size in six successive instars, and body-length in eight instars, we had some degree of repeatability of the estimates, which allows one to judge their quality.

$V_{\mathrm{A}}$ could only be calculated for mother clones, not for the daughters. Thus, comparisons of narrow-sense heritabilities before and after the sexual phase were not possible with our design. Age at maturity was transformed to natural logs. All estimates were calculated for the low food and the high food environment separately. $V_{\mathrm{A}}$ and $V_{\mathrm{G}}$ are expressed as percentages of $V_{\mathrm{P}}$ and thus represent narrow- and broad-sense heritability (Falconer, 1981), respectively.

\section{Results}

\section{Electrophoresis}

Typing of laboratory clones and individuals from the field sample revealed two alleles in Pgi and Amy and three alleles in Est. Frequencies of the least common alleles in Est and Amy were low and no homozygotes for these alleles were observed (Table 1).

Since strains of Daphnia pulex are known which produce ephippia without fertilization (pseudosexual eggs), it is important to know about the reproductive mode of our clones. Differences in the genotypes of our mothers and daughters (Table 1) confirmed our expectation that the daughter clones were produced truly sexually.

Table 1 Genotypic frequencies of mother clones, their sexually produced daughter clones and of samples taken at 21 May 1990 from a field population. Mother clones were collected on the same day, daughter clones originated from their ephippia hatched later in the laboratory. Expected frequencies of daughter clones were calculated from the allele frequencies of field sample ephippial females and males

\begin{tabular}{|c|c|c|c|c|c|c|c|}
\hline \multirow{3}{*}{\multicolumn{2}{|c|}{ Sample }} & \multicolumn{3}{|c|}{ Field sample } & \multicolumn{3}{|c|}{ Laboratory clones } \\
\hline & & \multirow{2}{*}{$\begin{array}{l}\text { Non-eph. } \\
\text { females }\end{array}$} & \multirow{2}{*}{$\begin{array}{l}\text { Ephippial } \\
\text { females }\end{array}$} & \multirow[b]{2}{*}{ Males } & \multirow[b]{2}{*}{ Mothers } & \multicolumn{2}{|l|}{ Daughters } \\
\hline & & & & & & Observed & Expected \\
\hline \multicolumn{8}{|c|}{ Locus } \\
\hline \multirow[t]{3}{*}{ Pgi } & 11 & 2 & 6 & 4 & 8 & 5 & 4.0 \\
\hline & 12 & 21 & 15 & 22 & 13 & 16 & 11.3 \\
\hline & 22 & 24 & 8 & 14 & 2 & 2 & 7.7 \\
\hline \multirow[t]{4}{*}{ Est } & 13 & 2 & 2 & 3 & 1 & 2 & 1.1 \\
\hline & 22 & 8 & 1 & 5 & 0 & 0 & 1.8 \\
\hline & 23 & 20 & 9 & 22 & 5 & 6 & 9.5 \\
\hline & 33 & 17 & 15 & 11 & 17 & 15 & 10.0 \\
\hline \multirow[t]{2}{*}{ Amy } & 11 & 41 & 24 & 36 & 21 & 18 & 20.4 \\
\hline & 12 & 6 & 3 & 5 & 2 & 5 & 2.5 \\
\hline
\end{tabular}


To judge the quality of our laboratory sample, we compared our mothers with females from the field sample. The mothers, which carried ephippia when taken from the field, did not differ electrophoretically from the ephippial females in the field, but differed at the Est and Pgi locus from the non-ephippial field females (Table 2). The ephippial and the non-ephippial field females differed only at the Pgi locus (cf. Hebert \& Ward, 1976). We conclude that our laboratory mother clones represent only the sexual females of the population, which differs genetically from the non-ephippial females. The genetic difference between ephippial and non-ephippial females was not reflected in the sample of males. The male sample did not differ from the field female samples (Table 2). Our daughter clones differed at the Pgi locus from the expected daughter genotype frequencies (calculated from ephippial female and male frequencies from the field sample, Table 2). Thus, we cannot completely rule out selection that may have occurred during storage or hatching of ephippia.

\section{Genetic variance components}

Age at maturity. Broad-sense heritability for age at maturity was significant for both food levels (high food: 22.60 per cent, $P=0.03$; low food: 40.2 per cent, $P=0.0005$ ), while narrow-sense heritability was low in both food levels (high: 0 per cent, ns; low: 4.4 per cent,
$P>0.5$ ). Non-additive components dominated the genetic variance of age at maturity.

Body-length. Length of adults was measured in eight successive instars beginning with the adolescent instar. In high food broad-sense heritability increased monotonically with increasing age, reaching 81 per cent in the seventh adult instar (Fig. 1). $V_{\mathrm{A}}$ increased parallel to $V_{\mathrm{G}}$ until the third adult instar and then drastically dropped to much lower values. However, none of the $V_{\mathrm{A}}$ estimates was significant. In low food the picture looked completely different. Total genetic variance fluctuated at low values, $V_{\mathrm{A}}$ was close to zero for all lengths.

Clutch size. $V_{\mathrm{G}}$ of clutch sizes varied around 30 per cent in high food and around 15 per cent in low food (Fig. 1). In five of the 12 estimates, $V_{\mathrm{A}}$ was larger than $V_{\mathrm{G}}$, in three of them the difference was pronounced. This appears to be wrong by definition because $V_{\mathrm{A}}$ should never exceed $V_{\mathrm{G}}$. However, one might expect this when additive and total genetic variance are about equal but subject to random estimation error. This was the case for $V_{\mathrm{A}}$, due to the nature of the estimation procedure. We concluded that for clutch size $V_{\mathrm{A}}$ and $V_{\mathrm{G}}$ were about equal. A combined probability test for independent tests of significance (Sokal \& Rohlf, 1981) was used to test if $V_{\mathrm{A}}$ is significant when all six $V_{\mathrm{A}}$

Table 2 Comparisons of genotype frequencies of the field sample and the laboratory clones using likelihood ratio test (Sokal \& Rohlf, 1981). For further description of sample see Table 1

\begin{tabular}{|c|c|c|c|c|c|c|c|c|c|}
\hline \multirow[b]{2}{*}{ Locus } & \multicolumn{3}{|l|}{$P g i$} & \multicolumn{3}{|l|}{ Est } & \multicolumn{3}{|c|}{ Amy } \\
\hline & $d . f$. & $\chi^{2}$ & $P<$ & d.f. & $\chi^{2}$ & $P<$ & d.f. & $\chi^{2}$ & $P<$ \\
\hline \multicolumn{10}{|c|}{ Mothers (laboratory) vs. ephippial females (field) } \\
\hline & 2 & 3.59 & ns & $2^{*}$ & 2.01 & ns & 1 & 0.08 & ns \\
\hline \multicolumn{10}{|c|}{ Mothers (laboratory vs. non-ephippial females (field) } \\
\hline & 2 & 19.30 & 0.0001 & $2^{*}$ & 9.78 & 0.01 & 1 & 0.26 & ns \\
\hline \multicolumn{10}{|c|}{ Ephippial (field) vs. non-ephippial females (field) } \\
\hline & 2 & 7.17 & 0.03 & $2^{*}$ & 2.91 & ns & 1 & 0.04 & ns \\
\hline \multicolumn{10}{|c|}{ Males vs. non-ephippial females (field) } \\
\hline & 2 & 2.80 & ns & $2^{*}$ & 1.20 & $\mathrm{~ns}$ & 1 & 0.007 & ns \\
\hline \multicolumn{10}{|c|}{ Males vs. ephippial females (field) } \\
\hline & 2 & 1.63 & ns & $2^{*}$ & 5.69 & ns & 1 & 0.02 & ns \\
\hline \multicolumn{10}{|c|}{ Daughters: expected vs. observed (laboratory) } \\
\hline & 2 & 6.42 & 0.05 & 3 & 5.49 & ns & 1 & 2.78 & ns \\
\hline
\end{tabular}

${ }^{*}$ Frequencies of the two smallest classes in Est were pooled. d.f. $=$ degrees of freedom. 

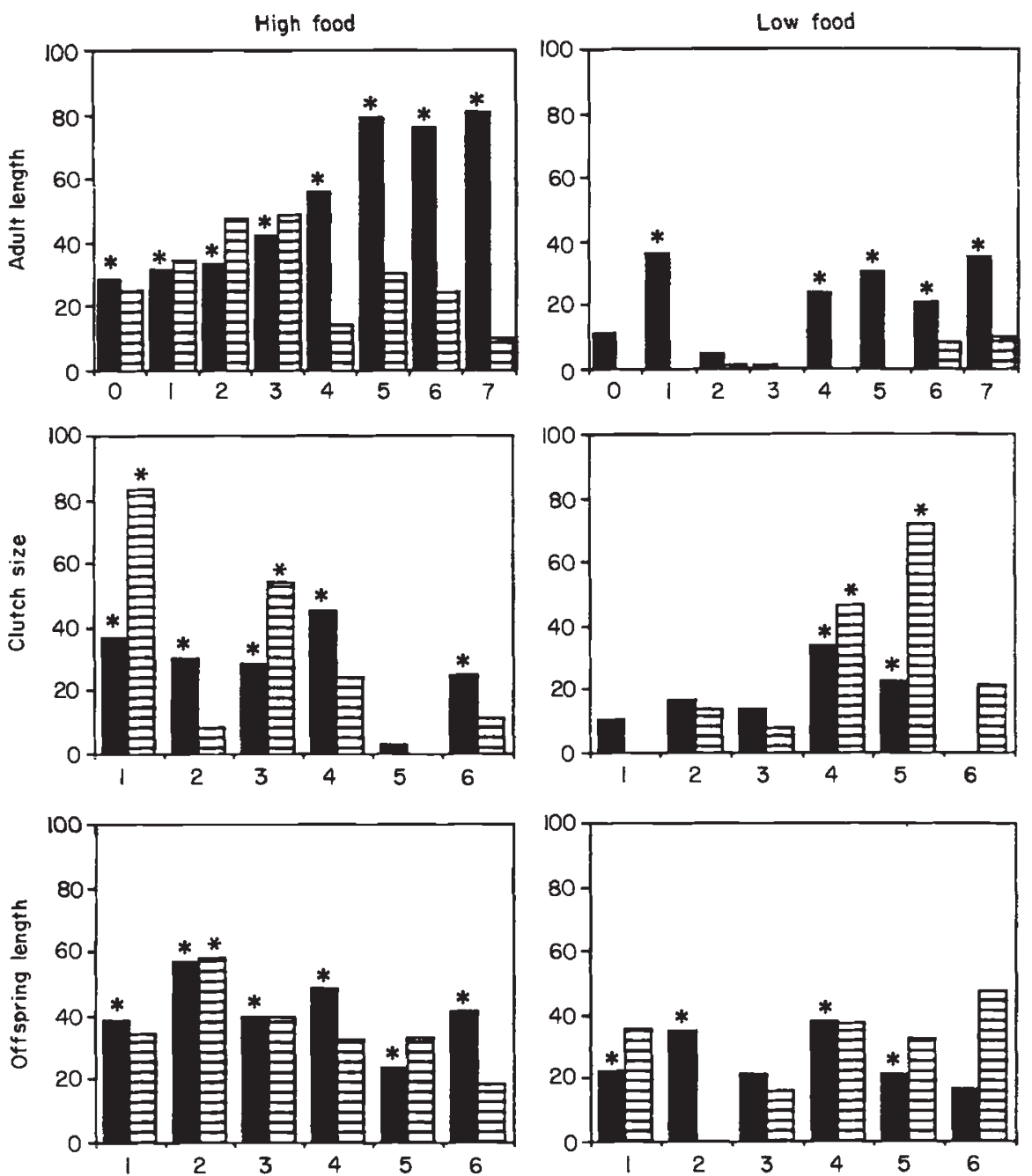

Fig. 1 Broad-sense (black bars) and narrow-sense (hatched bars) heritabilities of the adolescent instar (number 0 ), and the first seven adult instars (top row), for clutch sizes 1-6 (middle row) and for offspring lengths of clutches 1-6 (bottom row). Left: high food conditions; right: low food conditions. $*=P<0.05$. probabilities were combined. In both food levels combined probabilities were significant (high food: $\chi^{2}=32.3$, d.f. $=12, \quad P<0.01$; low food: $\chi^{2}=34.12$, d.f. $=12, P<0.01)$.

Offspring length at birth. For offspring lengths the picture was similar to that for clutch sizes (Fig. 1). Genetic variance was greater in high food than in low food and within environments no trend was visible. At both food levels, $V_{\mathrm{A}}$ was larger than $V_{\mathrm{G}}$ in three clutches and smaller in three clutches. Again we concluded that $V_{\mathrm{A}}$ and $V_{\mathrm{G}}$ were about equal, as for clutch size. $V_{\mathrm{A}}$ was only significant in clutch 2 in high food, but probability values for all six clutches in both environments were close to $P=0.05$. A combined probability test showed that in both food levels combined probabilities for $V_{\mathrm{A}}$ were significant (high food: $\chi^{2}=26.32$, d.f. $=12, P<0.01$; low food: $\chi^{2}=22.13$, d.f. $=12, P<0.05)$.

\section{Differences between mothers and daughters}

$V_{\mathrm{G}} \mathrm{s}$ were estimated for mother and daughter clones separately for all 21 traits at both food levels (Fig. 2). Genetic variance was significant $(P<0.05)$ for all but five traits in daughters and in all but eight in mothers. There was no consistent difference between the estimates of the two generations that would allow one to conclude that $V_{\mathrm{G}}$ is higher in daughters (Fig. 2). The correlation between mother and daughter estimates pooled from both food levels was positive $\left(r^{2}=0.43, n=42, P<0.01\right)$.

\section{Reducing possible variation in some traits}

Variance of Daphnia life-history traits may be greatly increased when females vary in the number of preadult instars (Ebert, 1991). To test this effect, we calculated the total phenotypic and the total genetic variance 


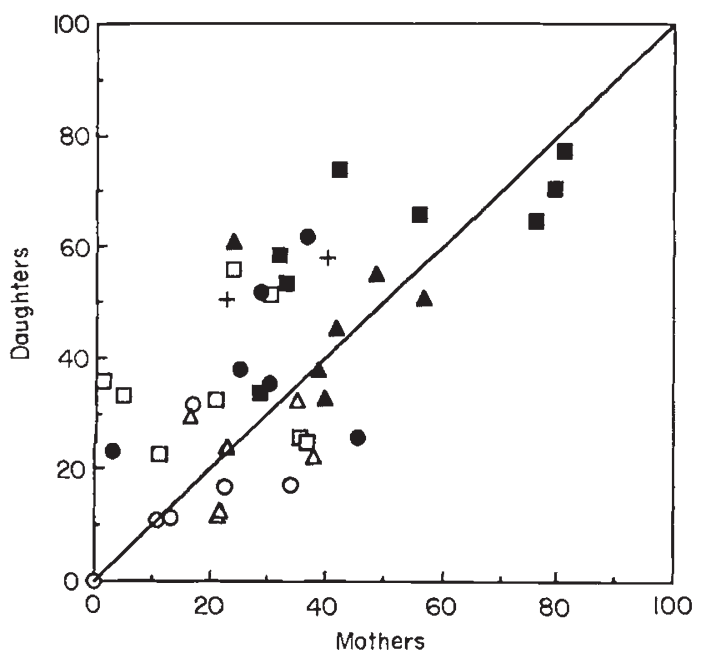

$\square$ Adult length, low

- Adult length, high

- Clutch size, low

- Clutch size, high

$\Delta$ Offspring length, low

$\Delta$ Offspring length, high

+ Age at maturity

Fig. 2 Total genetic variance (per cent) of daughter clones plotted vs. total genetic variance in mother clones. Age at maturity: the cross further to the top right is low food.

for all clones (including mother and daughter clones), once for the total dataset, and once only including individuals that had their first eggs in the fifth instar ( $=$ reduced data set; 81 per cent of all individuals in high food, 90 per cent in low food).

For age at maturity (log-transformed), phenotypic variance was reduced from 6.2 to 2.2 in high food and from 7.9 to 3.0 in low food (all values $\times 0.001$ ). Genetic variance was reduced from 2.8 to 0.3 in high and from 4.3 to 0.8 in low food. The stronger reduction of the genetic variance caused a drastic reduction of the broad-sense heritability from 46 to 16 per cent and from 55 to 28 per cent (all estimates $P<0.05$ ) in high and low food, respectively.

For adult length, total phenotypic variance was also lower in the reduced dataset (Fig. 3). Genetic variance did not differ in low food but was reduced in high food. Thus, broad-sense heritability increased in seven of eight cases in low food, and in two of eight in high food, when we used the reduced dataset.

The estimates for offspring length and clutch size showed hardly any change after removing females with other than five instars till maturity (Fig. 3). However, in high food most estimates of the reduced dataset were lower than for the total dataset. Thus, broad-sense heritability increased in seven of 12 cases in low, and in three of 12 cases in high food.
Of the 21 traits broad-sense heritability increased in only five of 21 cases in high, but in 14 cases in low food.

\section{Discussion}

This is the first time that broad-sense heritability has been measured at the end of an asexual phase and after subsequent sexual reproduction. The last generation after a period of asexual reproduction, represented by our mother clones, did not exhibit less genetic variance than their daughters, as was proposed by Lynch \& Gabriel (1983) and Lynch (1984). Possible explanations for this discrepancy might be that the selection pressure in our pond was less than the 10-20 per cent selective mortality per generation assumed by Lynch (1984), or that there were not enough generations between two successive sexual periods to reduce genetic variance. During extensive field sampling in 1989 and 1990, ephippial production was usually low (Ebert, in preparation). The population vanished in winter 1989/90 and reappeared in February 1990, most likely from hatching ephippia. Thus genetic diversity in February should have been high. The period from February to May may have been too short to reduce genetic diversity and perhaps is the reason why our study failed to identify a difference in levels of genetic variance between asexual lines and their sexual derivatives.

For most traits genetic variance components were higher in the high than in the low food environment (Figs 1 and 2). Heritability differences between environments have been described for birds (van Noordwijk, 1988; Henrich, 1989), and fruit flies (Gebhardt \& Stearns, 1988). Explanations for such differences have been proposed (e.g. Via, 1984; van Noordwijk \& Gebhardt, 1987; Henrich, 1989; Stearns, 1989), but there is no generally accepted explanation. Here we discuss three points that play a role under certain conditions.

1 Variation in juvenile development. Anderson (1932), Green (1956), Porter et al. (1983), Urabe (1988) and Ebert (1991), among others, have shown that the number of juvenile instars in Daphnia varies strongly depending on length at birth and environmental conditions. This introduces a large amount of variation, especially for adult body-length and age at maturity, inflating genetic and environmental variation. In our experiment daphniids matured in four to seven instars in high food and in four to eight instars in low food. Comparisons of the variances of the total dataset with those of a reduced dataset including only females that matured in their fifth instar showed that the impact of variation in the number of pre-adult instars varies 

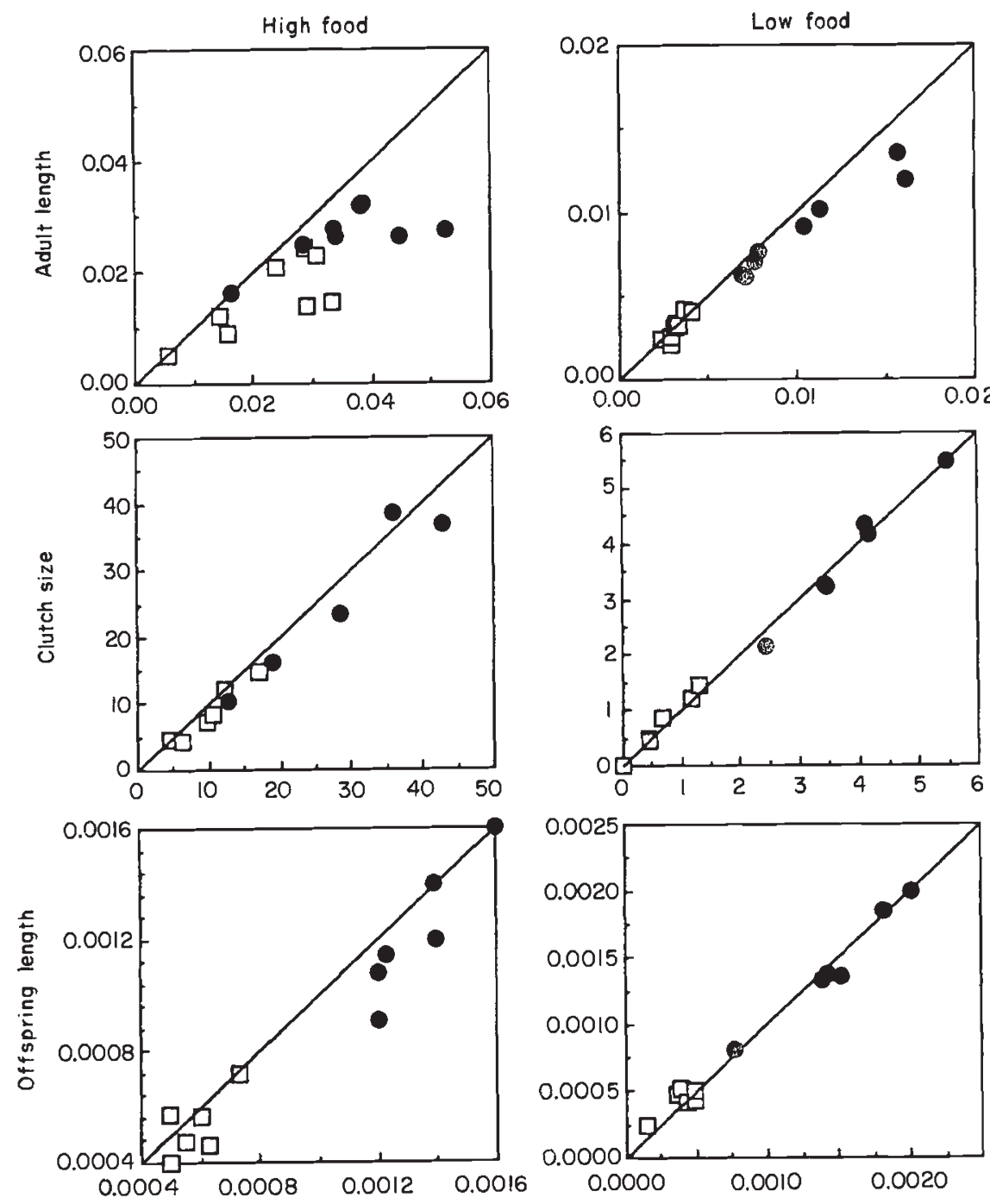

Fig. 3 Plot of total genetic ( $\square$ ) and the phenotypic ( variance of the complete dataset (horizontal axis) vs. the variances of a reduced dataset (vertical axis). The reduced dataset include only those females which laid their first eggs in their fifth instar. Left side: high food (H); right side: low food (L). Top panels: adult lengths; middle panels: clutches 1-6; bottom panel: offspring length of clutches $1-6$. For clutch size two dots are invisible because of complete overlap. with the trait considerably. For age at maturity and for adult length it was substantial; for clutch size and offspring length it made little difference. The strong effect on variance components for age at maturity can be explained by the large effect of additional instars on this trait. Ebert (1992) showed that a threshold mechanism regulates length at maturity by increasing the number of juvenile instars. However, each additional instar increases the variance strongly. This is the case for adult lengths and for age at maturity (Ebert, 1992).

Reducing the dataset also affected broad-sense heritabilities. Low food estimates were less reduced, or even increased, relative to the high food estimates of the same trait. We do not know if this would be true in general. Separating groups of females with equal numbers of juvenile instars is a good tool for analysing life-history variation in Daphnia (Anderson, 1932;
Ebert, 1991), but it can only be used in the laboratory and does not represent the conditions under which selection takes place in natural populations.

The number of juvenile instars varies with the environment in many arthropods, including spiders (Deevey, 1949), locusts (Uvarov, 1966), lepidopterans (Clare \& Singh, 1991) and decapods (Hartnoll, 1985). Thus, the pattern of increase described here - in phenotypic variation due to variance in the maturation instar - may be found among other arthropods as well. 2 Impact of measurement error on the total variance. The unexplained variance can be partitioned into the variance component due to measurement error, $V_{\mathrm{EM}}$, and the remaining unexplained variance. When $V_{\mathrm{EM}}$ stays the same over different environments (we believe that this was the case), but the total phenotypic variance changes, $V_{\mathrm{EM}}$ represents different proportions of $V_{\mathrm{P}}$ in different environments and thus causes all 
other variance components to change. For example the total variance of clutch sizes and adult lengths were much larger in high than in low food (compare $V_{\mathrm{P}}$ between food levels in Fig. 3), and thus the proportion of $V_{\mathrm{EM}}$ in low food were larger than in high food. Heritabilities in low food are therefore reduced. This effect becomes large when $V_{E M}$ becomes large and the difference of $V_{\mathrm{P}}$ between environments is large. For traits like age at maturity, which have naturally a large estimation error (the errors in estimating birth time and maturation time combine), this effect can be large.

3 Targeted growth. The heritabilities of adult lengths differ from the other traits in two respects. First, they were the highest in high food and the lowest in low food, and secondly, $V_{\mathrm{G}}$ in high food strongly increased with age. A similar pattern has been observed in other studies (Hutt, 1949; Ricklefs \& Peters, 1979; van Noordwijk, 1988; Henrich, 1989).

Daphnia growth is indeterminate, slows down in older animals, and is poor in poor feeding conditions (Taylor, 1985; Urabe, 1988; Lynch, 1989). In low food our females were much smaller than in high food. Hutt (1949), Ricklefs \& Peters (1979) and van Noordwijk et al. (1988) proposed that the maximum size (the asymptote in growth) an organism can reach in good conditions may display more genetic variation, for when growth is poor, animals cannot reach the asymptote and size is influenced largely by the environment thus, heritability of size is low (van Noordwijk, 1988; Henrich, 1989). In good conditions, size increases with age and the genetic asymptote is approached, the influence of the environment on growth becomes less and heritability for size is consequently high. This could possibly explain the difference in heritabilities in adult length between food levels found in this study.

The results show that heritabilities of life-history traits differ among environments. Daphnia live under variable environmental conditions and this variation should be included in the genetic analysis of life-history traits. Prediction of the response to selection needs to take the environment into account, especially for bodylength, which is assumed to be under high selection pressure throughout the year (Lynch, 1977, 1980). The analysis of heritabilities of reaction norms is the topic of the successive paper.

\section{Acknowledgements}

We thank A. J. van Noordwijk, B. Hellriegel, P. D. N. Hebert and two anonymous reviewers for comments on earlier versions of the manuscript and for improving the language. Special thanks to M. Bürki for laboratory assistance. The work was supported by Swiss Nationalfond grant No. 3.643.0.87 and No. 3100-028511-01.

\section{References}

ANDERSON, B. G. 1932. The number of pre-adult instars, growth, relative growth, and variation in Daphnia magna. Biol. Bull., 63, 81-98.

BUlmer, M. G. 1985. The Mathematical Theory of Quantitative Genetics. Clarendon Press, Oxford.

CLARE, G. K. AND SINGH, P. 1991. Variation in the number of larval instars of the brownheaded leafroller, Ctenopseustis obliquana (Lepidoptera: Tortricidae) at constant laboratory temperatures. $N Z$ J. Zool., 17, 141-146.

DE MEESTER, L. 1991. An analysis of the phototactic behaviour of Daphnia magna clones and their sexual descendants. Hydrobiol., 225, 217-227.

DEEVEY, G. B. 1949. The developmental history of Latrodectus mactans (Fabr.) at different rates of feeding. Am. Midl. Nat., 42, 189-219.

EBERT, D. 1991. The effect of size at birth, muturation threshold and genetic differences on the life-history of Daphnia magna. Oecologia (Berl.), 86, 243-250.

EBERT, D. 1992. A food-independent maturation threshold and size at maturity in Daphnia magna. Limnol. Oceanogr., 37, 878-881.

FALCONER, D. S. 1981. Introduction to Quantitative Genetics. Longman, London.

GEBHARDT, M. D. AND STEARNS, S. C. 1988. Reaction norms for developmental time and weight at eclosion in Drosophila mercatorum. J. Evol. Biol., 1, 335-354.

GREEN, J. 1954. Size and reproduction in Daphnia magna (Crustacea: Cladocera). Proc. Zool. Soc. Lond., 124, 535-545.

GREEN, J. 1956. Growth, size and reproduction in Daphnia (Crustacea: Cladocera). Proc. Zool. Soc. Lond., 126, 173-204.

HARTNOLL, R. G. 1985. Growth, sexual maturity and reproductive output. In: Wenner, A. M. (ed.) Factors in Adult Growth, Balkema, Rotterdam, pp. 101-128.

HEBERT, P. D. N. AND WARD, R. D. 1976. Enzyme variability in natural populations of Daphnia magna IV. Ecological differentiation and frequency changes of genotypes at Audley End. Heredity, 36, 331-341.

HENRICH, S. 1989. The genetical ecology of nestling growth in the Great Tit (Parus major L.). Ph.D. Thesis, University of Basel.

hUTT, F. B. 1949. Genetics of Fowl. McGraw-Hill Book Company, New York.

LYNCH, M. 1977. Fitness and optimal body size in zooplankton populations. Ecology, 58, 763-774.

LYNCH, M. 1980. The evolutin of cladoceran life histories. Quart. Rev. Biol., 55, 23-42.

LYNCH, M. 1984. The limits to life history evolution in Daphnia. Evolution, 38, 465-482.

LYNCH, M. 1985. Spontaneous mutations for life-history characters in an obligate parthenogen. Evolution, 39, 804-818.

LYNCH, M. 1989. The life history consequences of resource depression in Daphnia pulex. Ecology, 70, 246-256.

LYNCH, M. AND GABRIEL, w. 1983. Phenotypic evolution and parthenogenesis. Am. Natural., 122, 745-764. 
maynard smith, J. 1978. The Evolution of Sex, Cambridge University Press, Cambridge.

VAN NOORDWIJK, A. J. 1984. Quantitative genetics in natural populations of birds illustrated with examples from the Great Tit, Parus major. In: Wöhrmann, K. \& Loeschke, V. (eds) Population Biology and Evolution, Springer Verlag, Berlin, pp. 67-79.

VAN NOORDWIJK, A. J. 1988. Sib competition as an element of genotype-environment interaction for body size in the Great Tit. In: de Jong, G. (ed.) Population Genetics and Evolution, Springer, Berlin, pp. 124-137.

VAN NOORDWIJK, A. J., VAN BALEN, J. H. AND SCHARLOO, W. 1988. Heritability of body size in a natural population of the Great Tit (Parus major) and its relation to age and environmental conditions during growth. Genet. Res. Camb., 51, 149-162.

VAN NOORDWIJK, A. J. AND GEBHARDT, M. 1987. Reflections on the genetics of quantitative traits with continuous environmental variation. In: V. Loeschcke (ed.) Genetic Constraints and Adaptive Evolution, Springer, Berlin, pp. 73-90.

PORTER, K. G., ORCUTT, J. D. AND GERRITSEN, J. 1983. Functional response and fitness in a generalist filter feeder, Daphnia magna (Cladocera: Crustacea). Ecology, 64, 735-742.

RICKLEFS, R. E. AND PETERS, s. 1979. Intraspecific variation in growth rate of nestling European starlings. Bird-Banding, 50, $338-348$.
SAS INSTITUTE INC. 1990. SAS/STAT, Version 6. Cary, NC: SAS Institute Inc.

SOKAL, R. R. AND ROHLF, F. J. 1981. Biometry, 2nd edn. Freemann, New York.

STEARNS, S. C. 1989. The evolutionary significance of phenotypic plasticity. Bioscience, 39, 436-445.

TAYLOR, B. E. 1985. Effects of food limitation on growth and reproduction of Daphnia. Arch. Hydrobiol. Beih. Ergeb. Limnol., 21, 285-296.

URABE, J. 1988. Effect of food conditions on the net production of Daphnia galeata: Separate assessment of growth and reproduction. Bull. Plankton Soc. Japan, 35, $159-174$.

UVAROV, B. 1966. Grasshoppers and Locusts. University Press, Cambridge.

VRIJENHOEK, R. C. 1984. Ecological differentiation among clones: The frozen niche variation model. In: Wöhrmann, K. \& Loeschke, V. (eds) Population Biology and Evolution, Springer, Berlin, pp. 217-231.

VIA, s. 1984. The quantitative genetics of polyphagy in an insect herbivore. I. Genotype-environment interaction in larval performance on different host plant species. Evolution, 38, 881-895.

WOLF, H. G. 1982. A comparison of different electrophoretic techniques for the detection of isoenzymes in single daphnids. Arch. Hydrobiol., 95, 521-531. 